\title{
Developing and testing a nursing home end -of -life care chart audit tool
}

\author{
Genevieve N. Thompson ${ }^{1 *}$, Susan E. McClement ${ }^{1}$, Nina Labun ${ }^{2}$ and Kathleen Klaasen ${ }^{3}$
}

\begin{abstract}
Background: Nursing home $(\mathrm{NH})$ administrators need tools to measure the effectiveness of care delivered at the end of life so that they have objective data on which to evaluate current practices, and identify areas of resident care in need of improvement.

Methods: A three-phase mixed methods study was used to develop and test an empirically derived chart audit tool aimed at assessing the care delivered along the entire dying trajectory.

Results: The Auditing Care at the End of Life (ACE) instrument contains 27 questions captured across 6 domains, which are indicative of quality end-of-life care for nursing home residents.

Conclusions: By developing a brief chart audit tool that captures best practices derived from expert consensus and the research literature, $\mathrm{NH}$ facilities will be equipped with one means for monitoring and assessing the care delivered to dying residents.
\end{abstract}

Keywords: Palliative care, Nursing home, Quality of care, Audit tool, Tool development, Tool validation, Focus groups

\section{Background}

Nursing homes (NHs) have increasingly become the final residence for a growing cohort of individuals living with a variety of chronic life-limiting conditions. The acuity and medical complexity of residents entering $\mathrm{NHs}$ is increasing; current estimates indicate that the average resident dies within 2 years after admission [1] and $81 \%$ of those admitted to $\mathrm{NHs}$ will die there [2-4]. Given this reality, care providers in NHs face the challenge and responsibility of providing residents with quality end-of-life care. $\mathrm{NH}$ administrators need tools to measure the effectiveness of care delivered at the end of life so that they have objective data on which to evaluate current practices, and identify areas of resident care in need of improvement. One way of obtaining such data is through a chart audit, since these audits are designed to improve patient care by identifying gaps in care through the systematic collection and

\footnotetext{
* Correspondence: genevieve.thompson@umanitoba.ca

${ }^{1}$ College of Nursing, Rady Faculty of Health Sciences, University of Manitoba, Winnipeg, MB R3T 2N2, Canada

Full list of author information is available at the end of the article
}

analysis of data [5]. Chart audits are routinely conducted in many areas of health care [6-8].

Though a limited number of studies have been conducted using chart audits to evaluate the quality of palliative care in hospital [9], primary care [10, 11], and hospice/home care [12], studies using audits in the $\mathrm{NH}$ setting are limited. A review of the literature identified only two research studies that have conducted a chart audit of the care of the dying in $\mathrm{NH}$ $[12,13]$. However, both focused only on the immediate time before death, and neither specifically focused on developing a chart audit tool that was designed for routine use in clinical practice. Since excellence in palliative/end-of-life care espouses attending to the physical, psychosocial, and spiritual needs of the dying longer than the imminently dying phase [14], a thorough understanding of the care a resident receives for their entire dying phase is essential to understanding the quality of care provided during this time.

In order to address the limitations of the studies conducted to date and to construct a clinically relevant audit tool, the overarching goal of this study was to develop and test an empirically derived chart audit 
tool aimed at assessing the care delivered along the entire dying trajectory. Specific objectives for this study were to: (1) identify items that are indicators of quality end-of-life care important for inclusion on a chart audit tool; (2) develop, validate, and refine the $\mathrm{NH}$ resident end of life audit tool informed by objective one; and (3) evaluate the acceptability and utility of the tool in practice.

\section{Methods}

A three-phase mixed methods study was conducted to address the study objectives. Using the procedures outlined by Steiner and Norman [15] for the development and testing of health measurement scales, the research team engaged several processes to meet the objectives: 1) a critical review of existing literature; 2) item generation; 3) selection of items and assessment of validity; 4) field trials; and 5) generation of a refined instrument. This study received ethical approval from the University of Manitoba Education/Nursing Research Ethics board.

\section{Phase I}

The purpose of phase one of the study was to generate a list of possible end of life data elements for a chart audit tool that would capture best practices in the provision of care to dying residents. Drawing on the expertise of our research team, along with a critical review of the literature on best practices in end-of-life care for residents dying in $\mathrm{NHs}$, the areas described in a framework for a good death by Bosek and colleagues [16] were used to determine broad headings under which items to include in the chart audit would be placed. These headings included pain and symptom management, clear decision making, preparation for death, and affirmation of the whole person. Discussion concerning the time frame in which to evaluate end-of-life care was guided by our review of the literature. The team also reviewed existing audit tools currently used within the local regional health authority in order to have a template for the range of items, the manner in which questions can be formatted, and the types of data that are best collected using an audit tool.

\section{Phase I analysis}

Following the methodology proposed by Gearing and colleagues [17], the information collected in phase one was collectively coded, categorized and synthesized to ensure items generated for inclusion on the draft audit tool were: 1) representative of the experience of a good death in the $\mathrm{NH}$ setting, common occurrences, and areas of significant concern,; 2) grouped under the broad conceptual domains that emerged in the review of the literature,; and 3) included both quantitative and qualitative items in order to capture the care delivered in the last month and week of life. For example, simple yes/no questions were used to indicate the presence of a specific symptom, and larger free text areas were provided to capture the type of psychosocial care provided to family members. At this point, by consensus of the research team, and guided by the review of the literature, it was decided that the audit tool would evaluate the care the resident received in their last month of life. The audit tool was formatted following the advice of Allison [5] and Banks [18] who stipulate that a welldesigned audit tool is designed to promote accuracy of data capture and to limit the likelihood of missing data.

\section{Phase II}

Phase two saw the development, validation, and refinement of the chart audit tool. A convenience sample of key decision makers, gerontological and palliative care clinicians involved in providing care to $\mathrm{NH}$ residents (either direct clinical care or administrative services) were recruited to participate in a focus group in order to provide feedback regarding the clarity, content, and scope of the audit tool.

The administrative staff at a large urban regional health authority long-term care program in central Canada, sent a letter of invitation to potential focus group participants via email. The invitation instructed them to email the study's research assistant directly to indicate their interest in taking part. The research assistant determined if the participant met eligibility criteria, clarified any questions regarding the study, and provided the details of the focus group such as date, time and location. The research assistant also provided participants with a copy of the draft chart audit tool to review prior to the focus group. Focus group participants signed a consent form and completed a demographic questionnaire prior to the start of the discussion.

During the focus groups, participants were invited to share any insights and concerns they had about the audit tool. Each question on the audit tool was systematically discussed to assess its clarity, relevance, and importance. The focus group was facilitated by the first author while detailed notes of the discussion were recorded by the research assistant. The focus group lasted $45 \mathrm{~min}$. The feedback obtained from participants regarding the clarity, relevance, and importance of the items along with any insights or concerns raised during the focus group was used to revise the tool. The final version of the tool was vetted by the research team prior to pilot testing, to review the items, and formatting of the draft audit tool.

\section{Phase II analysis}

In the course of conducting focus groups, critical appraisal of the draft audit tool was completed by gerontological and palliative care health care providers and 
administrators $(n=12)$. Focus group participants were on average 47 years old (median 49 years), with 23.95 years of experience in their profession (range 8-37 years) and 11.95 years working in long-term care (range 2-26 years). The group was comprised of registered nurses $(n=5)$, clinical nurse specialists $(n=2)$, a social worker $(n=1)$, a pharmacist $(n=1)$ and long-term care administrators $(n=3)$. All items on the audit tool were highly endorsed by the group, including the assessment period (i.e. last month of life). Minor revisions to the instrument questions were made to correct terminology (e.g., advance care planning levels of care) and minor corrections to the formatting of the tool were made based on comments derived from the research team.

\section{Phase III}

In the final phase of this study, a brief trial of the audit tool was conducted in order to assess the reliability, time to complete, and the acceptability and utility of the instrument (See Fig. 1). Four NH facilities participated in the testing of the tool from which a random sample of $20 \%(n=90)$ of their deceased residents' charts from between January and December 2012 were audited; a sample size recommended for chart audits [19]. Two chart auditors with clinical experience in palliative care/gerontology were trained in the use of the audit tool for this study. The auditors independently extracted data from four of the same charts derived from the overall sample, in order to assess for ambiguous or confusing information on the audit tool. The abstracted data was compared for evidence of agreement on major variables. Every instance of variance was reviewed, using information in the original chart as the reference for further discussion [20]. The main challenge identified was that assessing end of life symptom management in the last month of life required too much data abstraction from

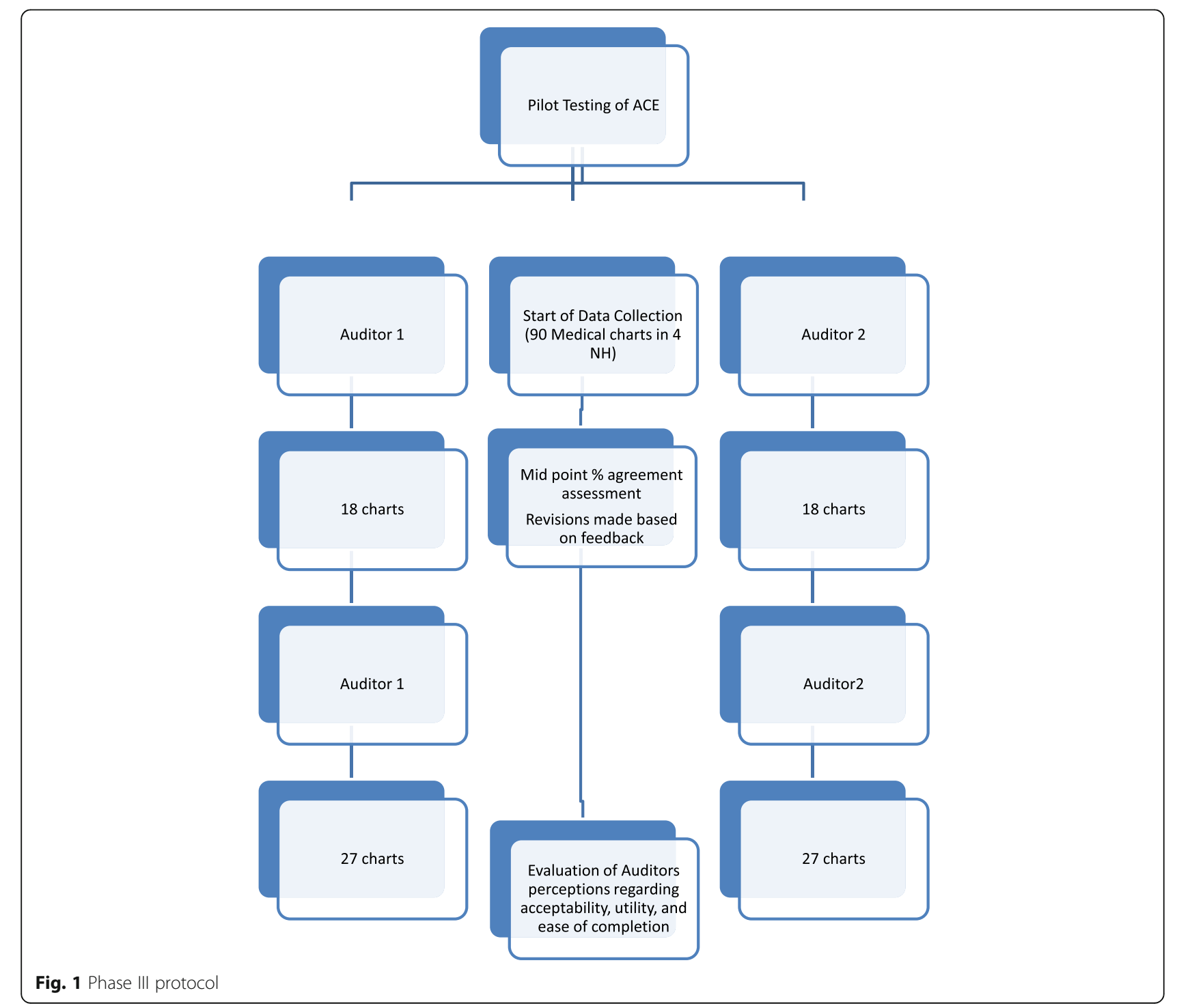


the chart, contributing to an unacceptably long completion time of the tool (on average $73 \mathrm{~min}$ ). Based on discussions between the auditors and research team, the period of symptom management assessment was changed to focus on the last week of life, while the remainder of the items on the tool continued to assess care provided in the last month of life.

Once consensus was reached between the chart auditors and research team as to the clarity of the items on the audit tool, the auditors independently completed 18 of the same charts in order to assess inter-rater reliability. Once those charts were analyzed, each auditor independently abstracted a sub-sample of the remaining charts $(n=58)$. Each auditor kept a journal detailing any difficulties they encountered while using the tool, suggestions for refining the tool, and the general ease of use of the tool.

\section{Phase III analysis}

The reliability of the chart audit tool was assessed through the evaluation of percentage agreement. This method was chosen since calculation of inter-rater reliability using Cohen's kappa (Kappa) ratings is dependent upon the distribution of the data; when data are skewed, for example by raters selecting the same response categories, reliability measures are low [21]. The percentage agreement was calculated from the number of ratings with agreement on the 18 charts coded at mid-point. For each item on the instrument, a percentage agreement of $80 \%$ or greater was considered to indicate reliability. The average time to complete a chart audit was computed based on the total time required to extract data from each chart and the number of charts reviewed. The journal notes kept by the auditors and from the meetings with the research team were coded for major themes using content analysis and constant comparative techniques to assess the acceptability, utility, and ease of using the chart audit tool [22].

\section{Results}

The final version of the instrument was named the Auditing Care at the End of Life (ACE) instrument, and it contains 27 questions captured across 6 domains (Table 1). These domains were conceptualized based on the review of the literature (occurrence and management of symptoms; acknowledgment of and preparation for dying; evidence of advance-care planning; attending to spiritual health and cultural aspects of resident care) and to provide context for the care being audited (resident demographics, the factors surrounding the death [e.g. place of death, cause of death, hospitalizations]). Questions were developed for each of these six domains that captured best practices in the delivery of end-of-life care.
Table 1 Example ACE tool domains and questions

Domain 1: Demographics

- Date of birth

- Date of death

- Gender

- Length of NH stay (in months)

Domain 2: Situation around death

- Indication on health record that death was expected? (YES/NO)

- Place of death (NH/Chronic Care/Acute Care/Palliative Care Unit)

- Was the resident transfered to acute care in their last month of life? (YES/NO)

Domain 3: Clear decision making

- Was there an Advance Care Plan? (YES/NO)

- Any changes to the Advance Care Plan made at last review? (YES/NO)

- Was there a Health Care Directive (YES/NO)

Domain 4: Preparation for death

- Is there evidence in the progress notes that staff recognized changes in the resident's condition that acknowledged that end of life was near? (YES/NO)

- Were there changes or adjustments made to the resident's physician/NP orders in the last month of life? (YES/NO)

- Were there any medication changes made in the last week of life? (YES/NO)

- Is there evidence in the progress notes that psychosocial support was provided to family members or friends during the dying experience? (YES/NO)

- Is there evidence in the progress notes of communication with family or friends about end-oflife care? (YES/NO)

Domain 5: Spiritual health and cultural aspects of care

- Evidence of resident's or family wishes regarding rites and rituals, or spiritual considerations acted upon (e.g., minister/pastor called, last rites administered)? (YES/NO)

- Resident's spiritual health preferences documented? (YES/NO)

Domain 6: Symptoms and symptom management through the death

- Is there evidence that Pain was assessed?(YES/NO)

- If a symptom (physical or psychological) is present, describe the managment.

- Personal Care/Comfort Provided in last week of life (e.g.: bathing, mouth care, positioning; incontinence care)?(YES/NO)

- Were consults made for other resources (e.g. Social Work, Volunteers, Clinical Nurse Specialists, Speech Language Pathologist)? (YES/NO)

In the pilot testing of the ACE instrument, the average time to complete an audit of one resident chart was $28.2 \mathrm{~min}$ (range: $15-60 \mathrm{~min}$ ). The percentage agreement by the raters with the 27 questions on the 18 charts ranged from 61 to $100 \%$ (see Table 2). Overall, the two auditors found the instrument easy to use however, the question on symptom management was the most "problematic". For example, the auditors noted that it was frequently difficult to read the handwriting in the chart, that often a standard tool for pain assessment was not used (though it was noted in the progress notes that the resident was in pain), and that rarely was it noted that follow up or evaluation regarding the effectiveness of an intervention occurred (e.g. administrating pain medication). 
Table 2 Percentage agreements between auditors on the ACE items

\begin{tabular}{|c|c|c|c|}
\hline $\begin{array}{l}\text { Instrument } \\
\text { item \# }\end{array}$ & $\begin{array}{l}\text { Number of scores } \\
\text { in agreement } \\
(n=18)\end{array}$ & $\begin{array}{l}\text { Percent } \\
\text { agreement }\end{array}$ & $\begin{array}{l}\text { Description of } \\
\text { question on ACE }\end{array}$ \\
\hline 6 & 18 & 100 & $\begin{array}{l}\text { Indication on health } \\
\text { record death was expected }\end{array}$ \\
\hline 9 & 18 & 100 & Place of death \\
\hline 10 & 18 & 100 & $\begin{array}{l}\text { Was the resident transferred } \\
\text { to acute care (ED) in the last } \\
\text { month of life? }\end{array}$ \\
\hline 11 & 18 & 100 & $\begin{array}{l}\text { Was there a Health Care } \\
\text { Directive? }\end{array}$ \\
\hline 12 & 18 & 100 & $\begin{array}{l}\text { Was there an Advance Care } \\
\text { Plan (ACP)? }\end{array}$ \\
\hline $12 a$ & 17 & 94 & Goals of care chosen \\
\hline 14 & 15 & 83 & $\begin{array}{l}\text { Any changes made to the last } \\
\text { ACP? }\end{array}$ \\
\hline 15 & 18 & 100 & $\begin{array}{l}\text { Is there evidence that EOL was } \\
\text { near? }\end{array}$ \\
\hline 16 & 16 & 88 & $\begin{array}{l}\text { Were there changes to resident's } \\
\text { orders in the last month? }\end{array}$ \\
\hline 17 & 18 & 100 & $\begin{array}{l}\text { Were there medication } \\
\text { changes in the last week? }\end{array}$ \\
\hline 18 & 15 & 83 & $\begin{array}{l}\text { Is there evidence of } \\
\text { communication with family? }\end{array}$ \\
\hline 19 & 17 & 94 & $\begin{array}{l}\text { Is there evidence that } \\
\text { psychosocial support was } \\
\text { provided to the family? }\end{array}$ \\
\hline 20 & 16 & 88 & $\begin{array}{l}\text { Resident's spiritual health } \\
\text { preferences documented? }\end{array}$ \\
\hline 21 & 15 & 83 & $\begin{array}{l}\text { Evidence of resident's or } \\
\text { family wishes regarding } \\
\text { rites and rituals, spiritual } \\
\text { considerations acted upon? }\end{array}$ \\
\hline 22 & 17 & 94 & $\begin{array}{l}\text { Is there evidence that pain } \\
\text { was assessed? }\end{array}$ \\
\hline $24 a$ & 13 & 71 & Pain present? \\
\hline $24 b$ & 18 & 100 & Nausea present? \\
\hline $24 c$ & 16 & 88 & Vomiting present? \\
\hline $24 d$ & 18 & 100 & Constipation present? \\
\hline $24 \mathrm{e}$ & 15 & 83 & Diarrhea present? \\
\hline $24 f$ & 17 & 94 & Dysphagia present? \\
\hline $24 \mathrm{~g}$ & 15 & 83 & Dyspnea present? \\
\hline $24 \mathrm{~h}$ & 15 & 83 & Respiratory congestion? \\
\hline $24 i$ & 14 & 77 & Cough present? \\
\hline $24 j$ & 13 & 72 & Dry mouth present? \\
\hline $24 \mathrm{k}$ & 11 & 61 & Fever present? \\
\hline 241 & 13 & 72 & Skin breakdown present? \\
\hline $24 \mathrm{~m}$ & 17 & 94 & UTI? \\
\hline $24 n$ & 17 & 94 & Edema present? \\
\hline 240 & 18 & 100 & Seizures present \\
\hline $24 p$ & 13 & 72 & Other symptom issues? \\
\hline $24 q$ & 17 & 94 & Depression present? \\
\hline $24 \mathrm{r}$ & 16 & 88 & Anxiety present \\
\hline
\end{tabular}

Table 2 Percentage agreements between auditors on the ACE items (Continued)

\begin{tabular}{|c|c|c|c|}
\hline $\begin{array}{l}\text { Instrument } \\
\text { item \# }\end{array}$ & $\begin{array}{l}\text { Number of scores } \\
\text { in agreement } \\
(n=18)\end{array}$ & $\begin{array}{l}\text { Percent } \\
\text { agreement }\end{array}$ & $\begin{array}{l}\text { Description of } \\
\text { question on } A C E\end{array}$ \\
\hline $24 \mathrm{~s}$ & 18 & 100 & Agitation present? \\
\hline $24 \mathrm{t}$ & 14 & 77 & Delirium present? \\
\hline $24 u$ & 13 & 72 & $\begin{array}{l}\text { Other psychosocial } \\
\text { symptoms present? }\end{array}$ \\
\hline $25 a$ & 16 & 88 & $\begin{array}{l}\text { Was mouth care provided in } \\
\text { the last week of life? }\end{array}$ \\
\hline $25 b$ & 14 & 77 & $\begin{array}{l}\text { Was bathing provided in the } \\
\text { last week of life? }\end{array}$ \\
\hline $25 c$ & 16 & 88 & $\begin{array}{l}\text { Was incontinence care } \\
\text { provided in the last week } \\
\text { of life? }\end{array}$ \\
\hline $25 d$ & 17 & 94 & $\begin{array}{l}\text { Was positioning provided } \\
\text { in the last week of life? }\end{array}$ \\
\hline 26 & 17 & 94 & $\begin{array}{l}\text { Was the Regional Health } \\
\text { End-of-Life Toolkit used? }\end{array}$ \\
\hline $27 a$ & 18 & 100 & $\begin{array}{l}\text { Was a consult made for } \\
\text { the Regional Palliative } \\
\text { care program? }\end{array}$ \\
\hline $27 b$ & 18 & 100 & $\begin{array}{l}\text { Was a consult made for } \\
\text { other MD or NP services? }\end{array}$ \\
\hline $27 c$ & 18 & 100 & $\begin{array}{l}\text { Was a consult made to the } \\
\text { site CNS? }\end{array}$ \\
\hline $27 d$ & 18 & 100 & $\begin{array}{l}\text { Was a consult made to the } \\
\text { Hospice Palliative care } \\
\text { volunteer program? }\end{array}$ \\
\hline $27 e$ & 18 & 100 & $\begin{array}{l}\text { Was a consult made to the } \\
\text { Facility Volunteers? }\end{array}$ \\
\hline $27 f$ & 17 & 94 & $\begin{array}{l}\text { Was a consult made to the } \\
\text { Speech Language Pathologist? }\end{array}$ \\
\hline $27 \mathrm{~g}$ & 17 & 94 & $\begin{array}{l}\text { Was a consult made to the } \\
\text { Spiritual Health Practitioner? }\end{array}$ \\
\hline $27 \mathrm{~h}$ & 16 & 88 & $\begin{array}{l}\text { Was a consult made to the } \\
\text { Registered Dietitian? }\end{array}$ \\
\hline $27 i$ & 18 & 100 & $\begin{array}{l}\text { Was a consult made to the } \\
\text { Regional NH CNS? }\end{array}$ \\
\hline $27 j$ & 14 & 77 & $\begin{array}{l}\text { Was a consult made to the } \\
\text { Therapeutic Recreation? }\end{array}$ \\
\hline $27 k$ & 18 & 100 & $\begin{array}{l}\text { Was a consult made to the } \\
\text { Respiratory Therapist? }\end{array}$ \\
\hline $27 \mid$ & 18 & 100 & $\begin{array}{l}\text { Was a consult made to the } \\
\text { Pharmacist? }\end{array}$ \\
\hline $27 \mathrm{~m}$ & 16 & 88 & $\begin{array}{l}\text { Was a consult made to Social } \\
\text { Work? }\end{array}$ \\
\hline $27 n$ & 12 & 66 & $\begin{array}{l}\text { Was a consult made to the } \\
\text { OT/PT/Rehab services? }\end{array}$ \\
\hline 270 & 18 & 100 & $\begin{array}{l}\text { Was a consult made to the } \\
\text { manager of food services? }\end{array}$ \\
\hline $27 p$ & 14 & 77 & Were other consults made? \\
\hline $27 q$ & 18 & 100 & $\begin{array}{l}\text { Was a consult made to the } \\
\text { Regional ethics committee? }\end{array}$ \\
\hline
\end{tabular}

CNS Clinical Nurse Specialist, NP Nurse Practitioner 


\section{Discussion}

To our knowledge, the ACE instrument is the first audit tool that has been developed to assess the domains of end-of-life care in $\mathrm{NH}$ residents and specifically designed to be used in clinical practice. The broad scope and detail covered by the instrument will allow administrators to clearly identify and measure the quality of care delivered to $\mathrm{NH}$ residents in their last month of life. This instrument was developed based on an extensive review of the literature on quality care of dying $\mathrm{NH}$ residents and validated through a rigorous process.

In the development of the instrument, as well as the testing of the face and content validity using focus group participants with considerable expertise and experience in long-term care, lends credibility to the tool. Further credibility of the instrument was established through pilot testing, where the auditors identified the instrument was easy to use and was completed in a relatively short time. The assessment of the inter-rater reliability showed high percentages of agreement between the two auditors for the majority of the questions on the instrument. Where discrepancies occurred, these were most frequently due to the auditors being required to make a judgment regarding the intent of the note documented. For example, often hydromorphone was documented as being given to the resident in the final days for "comfort" however, it was unknown if this was due to the resident experiencing pain, or for other undocumented reasons. Similarly, when the documentation included having given a family "up-dates," it was unknown if this qualified as having an end-of-life discussion or if information was simply being provided to the family. Further training of future users of the tool and the development of a manual to guide auditors in its use, would assist in resolving these issues.

While a detailed discussion of the specific findings using the ACE tool is beyond the scope of this paper, several observations made by the auditors deserve comment. First, that in many instances, no standardized tool for pain assessment could be found in the resident's chart is troubling, but not surprising given the breadth of research documenting the inadequacies in pain assessment and management in this setting [23-27]. In addition, the evaluation of the effectiveness of an intervention and reassessment of pain are critical nursing activities, yet several authors note limitations in this regard $[28,29]$. The lack of documentation that was noted by the auditors points to potential problems in the nursing documentation process, something that has been noted by other scholars [30, 31]. It also demonstrates that $\mathrm{NH}$ administrators need to reiterating to nursing staff, the importance of documenting the care they provide to the resident and their family. As the adage goes, if it is not documented, we have to assume it has not been done [32].

Some limitations with the instrument warrant comment. There may be some level of subjectivity associated with auditing charts [33], yet specific steps to limit subjectivity were taken as auditors assessed the care documented in the charts. For example, the tool has been developed to record occurrences, or lack thereof, of care; not to evaluate the care itself. Having auditors record whether there is documentation in the record that care has occurred or not and having them provide details surrounding the care delivered, eliminates the auditors need to make judgments regarding the acceptability of the care delivered. However, this then will require the individual who receives the chart audit reports, to then interpret and make a judgment as to the acceptability of the quality of care.

\section{Conclusion}

Auditing the care provided in the resident's last month of life aims to improve care through the identification of ineffective practices, enhance the quality of training provided to staff, and ensure the effective use of resources; all of which have the potential to change practice [10]. This study is significant since assessing the quality of care is an important activity for health care institutions to regularly undertake, yet there is a general recognition for the need to develop brief, quality measures for end-of-life care [14]. Also, gathering timely information is needed in order to monitor and improve the quality of end-of-life care, including valid and reliable data about the care provided, the recipients, the facilities, and the caregivers. By developing a brief chart audit tool that captures best practices derived from expert consensus and the research literature, $\mathrm{NH}$ facilities will be equipped with a valid means for monitoring and assessing the care delivered to residents in the last month of life. These assessments will help drive improvements in care by providing direction for staff education, the development of initiatives aimed at reducing ineffective practices, ensuring the optimal use of resources. These improvements will lead to a culture of care that aims to deliver the highest quality of care in the last phase of a resident's life.

\section{Abbreviations}

CNS: Clinical nurse specialist; NH: Nursing home; NP: Nurse practitioner

\section{Acknowledgements \\ The authors wish to express gratitude to research nurses Chloe Shindruk, Paula Black, and Veronika Zot for their dedication to the process of research. \\ Funding \\ This project was funded by a grant from the Manitoba Centre for Nursing and Health Research.}

Availability of data and materials

Please contact the corresponding author. 


\section{Authors' contributions}

GT was principal investigator for the study and project manager. The study was conceptualized by all authors. GT coordinated and oversaw data collection. GT and SM conducted data analysis. All authors were involved in reviewing study findings. All authors have contributed to drafting this paper and have read and approved the final manuscript.

\section{Ethics approval and consent to participate}

Ethical approval for this study was obtained from the University of Manitoba Education Nursing Research Ethics Board, Winnipeg Manitoba, Canada. Reference number E2013:079.

\section{Consent for publication}

Not applicable.

\section{Competing interests}

The authors declare that they have no competing interests.

\section{Publisher's Note}

Springer Nature remains neutral with regard to jurisdictional claims in published maps and institutional affiliations.

\section{Author details}

${ }^{1}$ College of Nursing, Rady Faculty of Health Sciences, University of Manitoba, Winnipeg, MB R3T 2N2, Canada. ${ }^{2}$ Donwood Manor, 171 Donwood Dr, Winnipeg, MB R2G 0V9, Canada. ${ }^{3}$ Winnipeg Regional Health Authority, 4th floor, 650 Main St, Winnipeg, MB R3B 1E2, Canada.

\section{Received: 23 February 2017 Accepted: 1 March 2018}

Published online: 15 March 2018

\section{References}

1. Doupe M, Fransoo R, Chateau D, Dik N, Burchill C, Soodeen R, et al. Population aging and the continuum of older adult care in Manitoba. Winnipeg: Manitoba Centre for Health Policy; 2011. Retrieved from: http://mchp-appserv.cpe. umanitoba.ca/reference/LOC Report WEB.pdf. Accessed 27 May 2014

2. Mitchell SL, Teno JM, Miller SC, Mor V. A national study of the location of death for older persons with dementia. J Am Geriatr Soc. 2005;53(2):299-305.

3. Temkin-Greener $H$, Zheng NT, Xing J, Mukamel DB. Site of death among nursing home residents in the United States: changing patterns, 2003-2007. J Am Med Dir Assoc. 2013;14(10):741-8.

4. Menec VH, Nowicki S, Blandford A, Veselyuk D. Hospitalizations at the end of life among long-term care residents. J Gerontol A Biol Sci Med Sci. 2009; 64(3):395-402

5. Allison JJ, Wall TC, Spettell CM, et al. The art and science of chart review. Jt Comm J Qual Improv. 2000;26:115-36.

6. Jennings N, Kansal A, O'Reilly G, et al. Time to analgesia for care delivered by nurse practitioners in the emergency department - a retrospective chart audit. Int Emerg Nurs. 2015;23:71-4. https://doi.org/10.1016/j.ienj.2014.07.002.

7. Ganesh A, Camden M, Lindsay $P$, et al. The quality of treatment of hyperacute ischemic stroke in Canada: a retrospective chart audit. CMA Open. 2014;2:E233-9. https://doi.org/10.9778/cmajo.20140067.

8. Purser L, Warfield K, Richardson C. Making pain visible: an audit and review of documentation to improve the use of pain assessment by implementing pain as the fifth vital sign. Pain Manag Nurs. 2014;15:137-42. https://doi.org/ 10.1016/j.pmn.2012.07.007.

9. Tsai LY, Li IF, Liu CP, et al. Application of quality audit tools to evaluate care quality received by terminal cancer patients admitted to a palliative care unit. Support Care Cancer. 2008;16:1067-74. https://doi.org/10.1007/s00520-007-0365-1.

10. Charlton $\mathrm{R}$, Smith $\mathrm{G}$, White $\mathrm{D}$, et al. Audit tools for palliative care services: identification of neglected aspects of care. Am J Hosp Palliat Care. 2002;19: 397-402.

11. Rogers MS, Barclay SI, Todd CJ. Developing the Cambridge palliative audit schedule (CAMPAS): a palliative care audit for primary health care teams. $\mathrm{Br}$ J Gen Pract. 1998:48:1224-7.

12. Solloway M, LaFrance $S$, Bakitas $M$, et al. A chart review of seven hundred eighty-two deaths in hospitals, nursing homes, and hospice/home care. J Palliat Med. 2005;8:789-96. https://doi.org/10.1089/jpm.2005.8.789.

13. Hall P, Schroder C, Weaver L. The last 48 hours of life in long-term care: a focused chart audit. J Am Geriatr Soc. 2002;50:501-6.
14. Dy SM, Kiley KB, Ast K, et al. Measuring what matters: top-ranked quality indicators for hospice and palliative care from the american academy of hospice and palliative medicine and hospice and palliative nurses association. J Pain Symptom Manag. 2015;49:773-81. https://doi.org/10. 1016/j.jpainsymman.2015.01.012.

15. Streiner DL, Norman GR. Health measurement scales: a practical guide to their development and use. New York: Oxford University Press; 2008.

16. Bosek MS, Lowry E, Lindeman DA, et al. Promoting a good death for persons with dementia in nursing facilities: family caregivers' perspectives. JONAS Healthc Law Ethics Regul. 2003;5:34-41.

17. Gearing RE, Mian IA, Barber J, et al. A methodology for conducting retrospective chart review research in child and adolescent psychiatry. J Can Acad Child Adolesc Psychiatry. 2006;15:126-34.

18. Banks NJ. Designing medical record abstraction forms. Int J Qual Health Care. 1998:10:163-7.

19. Worster A, Haines T. Advanced statistics: understanding medical record review (MRR) studies. Acad Emerg Med. 2004;11:187-92.

20. Eder C, Fullerton J, Benroth $\mathrm{R}$, et al. Pragmatic strategies that enhance the reliability of data abstracted from medical records. Appl Nurs Res. 2005;18: 50-4. https://doi.org/10.1016/j.apnr.2004.04.005.

21. de Vet HC, Mokkink LB, Terwee $C B$, et al. Clinicians are right not to like Cohen's kappa. BMJ. 2013;346:f2125. https://doi.org/10.1136/bmj.f2125.

22. Streubert Speziale H, Rinaldi CD. Qualitative research in nursing: advancing the humanistic imperative. 4th ed. Philadelphia: Wolters Kluwer Health/ Lippincott Williams \& Wilkins; 2011.

23. de Souto Barreto P, Lapeyre-Mestre M, Vellas B, et al. Potential underuse of analgesics for recognized pain in nursing home residents with dementia: a cross-sectional study. Pain. 2013;154:2427-31. https://doi.org/10.1016/j.pain. 2013.07.017.

24. Lin WC, Lum TY, Mehr DR, et al. Measuring pain presence and intensity in nursing home residents. J Am Med Dir Assoc. 2006:7:147-53. https://doi. org/10.1016/j.jamda.2005.08.005.

25. Monroe TB, Misra SK, Habermann RC, et al. Pain reports and pain medication treatment in nursing home residents with and without dementia. Geriatr Gerontol Int. 2014;14:541-8. https://doi.org/10.1111/ggi.12130.

26. Teno JM, Kabumoto G, Wetle $T$, et al. Daily pain that was excruciating at some time in the previous week: prevalence, characteristics, and outcomes in nursing home residents. J Am Geriatr Soc. 2004;52:762-7. https://doi.org/ 10.1111/j.1532-5415.2004.52215.x.

27. Sawyer $\mathrm{P}$, Lillis JP, Bodner EV, et al. Substantial daily pain among nursing home residents. J Am Med Dir Assoc. 2007;8:158-65. https://doi.org/10. 1016/j.jamda.2006.12.030

28. Coker E, Papaioannou A, Turpie I, et al. Pain management practices with older adults on acute medical units. Perspectives. 2008:32:5-12.

29. Samuels JG, Fetzer S. Pain management documentation quality as a reflection of nurses' clinical judgment. J Nurs Care Qual. 2009:24:223-31. https://doi.org/10.1097/NCQ.0b013e318194fcec.

30. Wang N, Hailey D, Yu P. Quality of nursing documentation and approaches to its evaluation: a mixed-method systematic review. J Adv Nurs. 2011;67: 1858-75. https://doi.org/10.1111/j.1365-2648.2011.05634.x.

31. Prideaux A. Issues in nursing documentation and record-keeping practice. Br J Nurs. 2011;20:1450-4. https://doi.org/10.12968/bjon.2011.20.22.1450.

32. Jefferies $D$, Johnson $M$, Griffiths $R$. A meta-study of the essentials of quality nursing documentation. Int J Nurs Pract. 2010;16:112-24. https://doi.org/10. 1111/j.1440-172X.2009.01815.x.

33. Larson J, Bjorvell C, Billing $E$, et al. Testing of an audit instrument for the nursing discharge note in the patient record. Scand J Caring Sci. 2004;18: 318-24. https://doi.org/10.1111/j.1471-6712.2004.00288.x 